\title{
ON THE USE OF PALLADIUM-HYDROGEN AS A REDUCING AGENT IN QUANTITATIVE ANALYSIS.
}

\author{
By Alfred C. Chapman.
}

(Read at the Meeting, November 2, 1904.)

SEEING that the chemical activity of the hydrogen "associated with" palladium in the so-called palladium-hydrogen was recognised by Graham more than thirty years ago, it is not a little strange that so few investigations should have been made for the purpose of ascertaining the possibility of utilizing this interesting substance in analytical processes involving reduction changes. As a source of pure hydrogen, as an absorbent in gas analysis, and occasionally as a means of obtaining hydrogen in a conveniently weighable form, palladium and palladium-hydrogen are not infrequently employed in the laboratory; but as an analytical reducing agent the latter substance is, so far as I am aware, rarely, if ever, made use of. In 1885 a thesis was presented to the University of Berne by Schwarzenbach and Kritschewsky dealing with this subject, and was apparently sent by the authors to Fresenius, who published an abstract of it in the Zeitschrift für analytische Chemie (xxv., 374, 375). I have not been able to obtain access to the original communication, but the above-mentioned abstract appears to have been a full one, and shows that the authors experimented with a number of reducible substances, and found that in several cases quantitative results could be obtained. Prior to this (1871), Böttger had shown in the course of a communication to the Naturforscher Versammlung of Rostock that potassium ferricyanide could be reduced to ferrocyanide, but does not appear to have done more. At the time when the investigation-of which an account is given in this paperwas commenced I was not aware of the work which had been done by the abovementioned authors; but as I have been unable to confirm some of their results, I have thought it well to repeat, as well as to extend, their observations. The palladium used in my experiments was the pure metal supplied by Messrs. Johnson and Matthey, and was employed in the form of foil of such thickness that a piece 2 inches square weighed about 8 grammes. A piece of thick palladium wire was welded to this for the purpose of supporting it in an electrolytic cell, and the foil was bent so as to enable it to be more readily introduced into the flask or other vessel in which the experiment had to be carried out. The palladium was in all cases charged by being made the negative electrode in an ordinary cell containing dilute sulphuric acid, the current being obtained either from the main through a suitable resistance or from accumulators. When fully charged (as evidenced by the rapid disengagement of hydrogen in the cell) the metal was washed, and at once introduced into the solution under examination, which was then boiled gently in a flask or covered beaker for the necessary time. Experiments showed that when charged electrolytically the palladium "took up" in all cases from 800 to 1,100 times its volume of gas, but the chemical activity of the hydrogen appeared to be more dependent on the physical condition of the metallic surface than upon the actual amount present. It was found, for example, that after having been used for a number of times the 
reducing action became distinetly less marked, but could be restored by heating the metal to redness (preferably in a current of hydrogen) and recharging.

IrON.

For experiments with this metal a solution of pure ferric chloride was prepared, containing 0.010137 gramme $\mathrm{Fe}$ in 1 c.c. Ten c.c. of this solution were diluted to about 100 c.c. with distilled water, from 10 to 20 c.c. of 25 per cent. sulphuric acid added, and the mixture boiled gently with the charged palladium. After complete reduction, which usually occurred with the above quantities in from twenty to thirty minutes, the metal was removed and washed, and the iron titrated in the usual way with standard potassium bichromate solution.

The following results were obtained :

$$
\begin{array}{ccccc} 
& & & \text { Found. } & \text { Present. } \\
\text { Fe } \ldots & \ldots & \ldots & 0.1002 \text { gramme } & \\
& 0.1022 \quad, & \\
& & & 0.1002 \quad, & 0.1013 \text { gramme } \\
& & & 0.1002 \quad, &
\end{array}
$$

In the following experiments weighed quantities of iron wire (99.8 per cent. Fe) were taken, converted into ferric chloride, and reduced with the charged palladium as above:

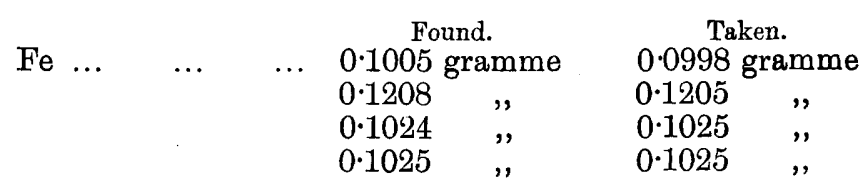

The following results were obtained with solutions of ferric sulphate (containing no chlorine) acidified with sulphuric acid, and reduced as above :

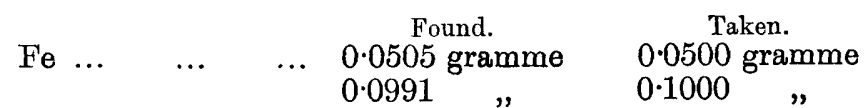

In technical analysis it happens very frequently that iron and aluminium are weighed together, either as hydroxides or phosphates, and it is in such cases a great convenience to be able to estimate the iron volumetrically, and to calculate the aluminium by difference.

The following experiments were therefore made for the purpose of ascertaining whether phosphoric acid or aluminium interfered in any way with the accuracy of the palladium-reduction process:

\begin{tabular}{|c|c|c|c|c|c|c|}
\hline \multirow{2}{*}{$\mathrm{Fe} \ldots$} & \multirow{2}{*}{$\ldots$} & & \multicolumn{2}{|c|}{$\begin{array}{c}\text { Found. } \\
0.0500 \text { gramme }\end{array}$} & \multicolumn{2}{|c|}{$\begin{array}{c}\text { Present. } \\
0.0500 \text { gramme }\end{array}$} \\
\hline & & & $\begin{array}{l}0.0494 \\
0.0500\end{array}$ & $"$ & $\begin{array}{l}0.0500 \\
0.0500\end{array}$ & $"$ \\
\hline
\end{tabular}

Series 1.-Ferric Phosphate dissolved in Dilute HCl.

Time of reduction, about thirty minutes. 
Series 2.-Fierric Phosphate with Aluminium Phosphate dissolved in $\mathrm{HCl}$.

\begin{tabular}{|c|c|c|c|c|}
\hline $\mathrm{Fe}$. & $\cdots$ & $\ldots$ & $\begin{array}{c}\text { Found. } \\
0.0247 \text { gramme }\end{array}$ & $\begin{array}{c}\text { Present. } \\
0.0250 \text { gramme }\end{array}$ \\
\hline & & & 0.0247 & 0.0250 \\
\hline
\end{tabular}

From the above experiments it will be seen that ferric can be completely and readily reduced to ferrous salts by charged palladium, and it will be obvious that, as none of the products of the reducing agent remain in the solution to be titrated, the end-reaction with ferricyanide is sharply marked. It is interesting in this connection to note that whilst palladium, when charged, is quite unacted upon by iron solutions, the uncharged metal dissolves readily in acid solutions of ferric chloride, the iron being at the same time reduced to the ferrous condition.

In the two following experiments known weights of pure iron were taken, dissolved in dilute hydrochloric, with the addition of a little nitric acid, evaporated twice to dryness with hydrochloric acid, and precipitated with ammonia. The ferric hydroxide was thoroughly washed to remove traces of nitrate, and dissolved in dilute hydrochloric acid. Into the pure ferric chloride solutions so obtained weighed pieces of uncharged palladium foil were introduced, and the liquids boiled until no further action occurred. The undissolved palladium was then removed, washed, dried, and weighed. The following results were obtained :

$$
\begin{array}{cccccc} 
& & & \text { Fe taken. } & \text { Pd dissolved. } & \begin{array}{c}
\text { Theory for Equation } \\
\text { given Below. }
\end{array} \\
1 \ldots & \ldots & \ldots & 0.100 \text { gramme } & 0.0945 \text { gramme } & 0.095 \text { gramme } \\
2 \ldots & \ldots & \ldots & 0.210 \text { ", } & 0.2020 \text {, } & 0.200 \text {, }
\end{array}
$$

The above numbers show that the reaction takes place in accordance with the equation :

$$
\mathrm{Pd}+2 \mathrm{FeCl}_{3}=\mathrm{PdCl}_{2}+2 \mathrm{FeCl}_{2} \text {. }
$$

On the other hand, when the charged palladium was used the loss was less than 1 milligramme in seven hours.

\section{Chromium.}

Acidified solutions of chromates were found to be completely reduced to the corresponding chromic compounds by palladium-hydrogen. In the following experiments known volumes of standard potassium bichromate solution were diluted with water, acidified with sulphuric acid, and boiled with the charged palladium in

\begin{tabular}{|c|c|c|c|c|c|}
\hline \multirow[t]{4}{*}{$\mathrm{Cr}$} & \multirow{2}{*}{$\cdots$} & \multirow{2}{*}{$\cdots$} & \multicolumn{2}{|c|}{$\begin{array}{c}\text { Found. } \\
0.1771 \text { gramme }\end{array}$} & \multirow[t]{5}{*}{$\begin{array}{c}\text { Present. } \\
0.1768 \text { gramme. }\end{array}$} \\
\hline & & & 0.1771 & ", & \\
\hline & & & 0.1773 & " & \\
\hline & & & $\begin{array}{r}0.1769 \\
0.1771\end{array}$ & $"$ & \\
\hline & & & 0.1771 & & \\
\hline
\end{tabular}
the usual way. After reduction the chromium was estimated as $\mathrm{Cr}_{2} \mathrm{O}_{3}$ :

\section{COPPER.}

When a dilute acidified solution of cupric chloride was boiled for some time in contact with charged palladium the colour gradually disappeared, and on testing the solution so obtained with potassium iodide, with potassium thiocyanate, and with 
ammonia, it was found that complete reduction to the cuprous state had occurred. When stronger cupric solutions were employed the cuprous chloride separated out in the crystalline state, the crystals being frequently of fair size, and often adhering to the surface of the palladium. This separation could, however, be prevented by adding to the copper solution before reduction a sufficient quantity of sodium chloride. Attempts were made to titrate these cuprous solutions with standard permanganate and bichromate solutions, but without success, the results being uniformly low and the end-points uncertain. In other experiments the reduced cuprous solution was added, with proper precautions, to an excess of recently-boiled ferric chloride solution, but attempts made to titrate the ferrous salt formed were not successful.

Titrations with iodide solutions in various ways also gave unsatisfactory results. To test the completeness of the reduction, the cuprous solutions, after treatment, were poured into a solution of potassium thiocyanate in excess, and the precipitated cuprous thiocyanate weighed either directly on a tared paper or after conversion into cuprous sulphide. It may be added that the precipitate was in all cases pure white-whether the solutions were cold or warm-and that there was no sign whatever of the formation of any of the cupric compound.

The following results were obtained :

\begin{tabular}{|c|c|c|c|c|c|c|}
\hline \multirow{4}{*}{$\mathrm{Cu} \ldots$} & \multirow{4}{*}{$\ldots$} & \multirow[t]{4}{*}{$\ldots$} & \multicolumn{2}{|c|}{ Found. } & \multicolumn{2}{|c|}{$\begin{array}{c}\text { Taken. } \\
0 \cdot 100 \text { gramme }\end{array}$} \\
\hline & & & $0 \cdot 100$ & , & $0 \cdot 100$ & \\
\hline & & & 0.099 & ", & $0 \cdot 100$ & $"$ \\
\hline & & & $0: 116$ & 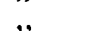 & 0.117 & \\
\hline
\end{tabular}

When the charged palladium was allowed to remain in contact with a cold aqueous solution of cupric sulphate for some hours it became coated with a deposit of metallic copper, and small patches could occasionally be observed in the experiments with the chloride carried out in the usual way. When uncharged palladium is heated in an acidified solution of cupric chloride, the solution gradually acquires, first, a deep olive-green, and then a reddish-brown colour, and is found to contain appreciable quantities of palladium, the cupric salt having undergone reduction at the same time.

Experiments were made similar to those described above in the case of ferric chloride, the quantities of palladium dissolved by solutions containing known weights of cupric chloride being determined. The following are the results obtained:

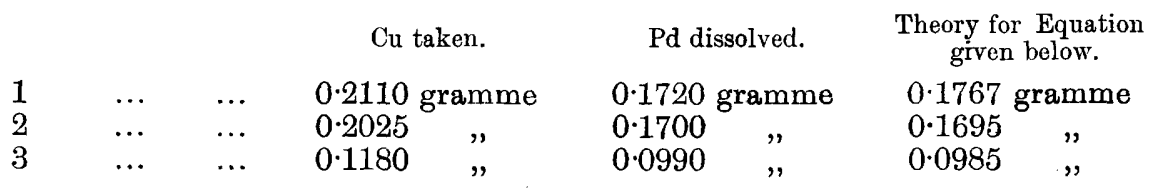

The above numbers are, therefore, closely in agreement with those required by the equation-

$$
2 \mathrm{CuCl}_{2}+\mathrm{Pd} .=2 \mathrm{CuCl}+\mathrm{PdCl}_{2} \text {. }
$$




\section{Mercury.}

On heating charged palladium for some hours in an acid solution of mercuric chloride, a dull gray film formed on the surface of the metal, which blackened on the addition of ammonia, showing that slight reduction to mercurous chloride had occurred. When this film was removed by rubbing, the surface of the palladium was found to present a number of brilliant spots, indicating, apparently, that metallic mercury had been formed. Dilute acidified solutions of mercuric chloride appear to be without action on the uncharged metal.

Tin.

With stannic chloride very slight reduction to the stannous condition occurred.

\section{Arsenid Acid.}

Even after boiling for three hours with fully-charged palladium, the arsenic acid had not undergone any appreciable reduction to arsenious acid, and in the case of neither compound could arseniuretted hydrogen be detected in the evolved gas.

\section{Manganese.}

Very dilute acidified solutions of potassium permanganate were completely reduced to manganous salts, but when the quantity of permanganate exceeded a few milligrammes the reduction to manganous salt was imperfect, hydrated oxide of manganese separating in the form of brown flakes or powder.

\section{Potassium Chlorate.}

A solution containing 1 gramme of pure recrystallized potassium chlorate per 100 c.c. was used. The following table will show the results obtained in six experiments, the time of contact with the charged palladium being one hour in each case, and a reflux condenser being attached to the reduction flask:

\begin{tabular}{|c|c|c|c|c|c|}
\hline $\begin{array}{c}\text { Experiment. } \\
1\end{array}$ & \begin{tabular}{l}
\multicolumn{3}{c}{ Condition of Solution. } \\
neutral $\ldots$
\end{tabular} & $\begin{array}{l}\text { Chlori } \\
0.0723\end{array}$ & $\begin{array}{l}\text { ken. } \\
\text { mme }\end{array}$ & $\begin{array}{l}\text { Chlorine } \\
0.03363\end{array}$ & $\begin{array}{l}\text { ind. } \\
\text { imme }\end{array}$ \\
\hline 2 & acid $\left(2\right.$ drops $\left.25 \% \mathrm{H}_{2} \mathrm{SO}_{4}\right)$ & 0.0723 & , & 0.04525 & " \\
\hline 3 & , $\quad\left(5\right.$ c.c. $\left.25 \% \mathrm{H}_{2} \mathrm{SO}_{4}\right) \ldots$ & 0.0723 & 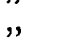 & $0 \cdot 05971$ & $"$ \\
\hline$\frac{4}{5}$ & " & 0.0723 & $"$ & 0.04671 & $"$ \\
\hline 6 & $\begin{array}{c}\text { (5 drops } 25 \text { c.c. } \mathrm{H}_{2} \mathrm{SO}_{4} \\
\text { every } 15 \text { minutes }) \\
\quad\left(10 \text { c.c. } 25 \% \mathrm{H}_{0} \mathrm{SO}_{4}\right)\end{array}$ & $\begin{array}{l}0.0723 \\
0.0723\end{array}$ & , & $\begin{array}{l}0.04550 \\
0.06778\end{array}$ & $”$ \\
\hline
\end{tabular}

It will be seen that the reduction of the chlorate was not complete in any case, the best result being 94 per cent. of the theoretical. In the case of the neutral solution and of those to which very little acid was added the reaction was very imperfect, and the hydrogen from the charged palladium is therefore less effective than the nascent hydrogen obtained by employing zinc and dilute sulphuric acid or a copperzinc couple.

\section{Potassium Perchlorate.}

Perchlorates in solution are well known to be very stable, and to undergo reduction with extreme difficulty. On boiling acidified solutions of pure potassium 
perchlorate with charged palladium, only traces of chloride were formed even after some hours.

\section{Bromates and Iodates.}

Attempts made to reduce bromates and iodates to the corresponding halides in neutral solutions were only partially successful, and even after a treatment lasting several hours the greater part of each of these salts was found to have remained unattacked.

\section{Potassium Nitrate.}

Five c.c. of a 1 per cent. solution of pure potassium nitrate were diluted to about 100 c.c. with water, acidified with $\mathrm{HCl}$, and treated with the charged palladium in the usual way. Even after boiling for two hours it was found that only about 10 per cent. of the nitrogen had been converted into ammonia, and the experiments were therefore abandoned.

\section{Potassium Ferricyanide.}

A solution containing 1 gramme of the pure recrystallized salt per 100 c.c. was employed in the following experiments. Known volumes of this solution were diluted with water, made alkaline with caustic potash, and boiled in contact with the charged palladium in small flasks or covered beakers. When the reduction was complete (with the quantities mentioned below, fifteen to twenty minutes was found to be sufficient) the palladium was removed and washed, the solution strongly acidified with sulphuric acid, and titrated in the cold with standard permanganate in the usual manner :

\begin{tabular}{|c|c|c|c|c|c|c|}
\hline \multirow[t]{5}{*}{$\mathrm{K}_{3} \mathrm{FeC}_{6} \mathrm{~N}_{6}$} & \multirow[t]{5}{*}{$\ldots$} & \multirow[t]{5}{*}{$\ldots$} & \multicolumn{2}{|c|}{$\begin{array}{c}\text { Found. } \\
0.2007 \text { gramme }\end{array}$} & \multicolumn{2}{|c|}{$\begin{array}{l}\text { Taken. } \\
0 \cdot 200 \text { gramme }\end{array}$} \\
\hline & & & 0.2006 & ," & $0 \cdot 200$ &, \\
\hline & & & $0 \cdot 2500$ & ", & 0.250 & $"$ \\
\hline & & & $0 \cdot 2500$ & " & $0 \cdot 250$ & $"$ \\
\hline & & & $0 \cdot 2303$ & & 0.230 & \\
\hline
\end{tabular}

In carrying out this method, it is well that the ferricyanide solution should be made only slightly alkaline, and that the treatment with palladium should not be continued longer than is necessary. Occasionally a slight trace of iron oxide (or hydroxide) separates during the boiling, and as this somewhat diminishes the sharpness of the end-point in the permanganate titration, it is better to filter the reduced solutions in all cases. I have assured myself by very careful experiments that this does not in the least interfere with the accuracy of the method, provided that the above-mentioned conditions are observed. It will be seen, then, from the above numbers that ferricyanides can be completely and readily reduced to ferrocyanides, and as the methods at present adopted in analytical operations for effecting this reduction are complicated and leave much to be desired, I think the palladium-hydrogen process will be found very useful.

\section{VANADIUM.}

The reduction of solutions of vanadium pentoxide for the purpose of volumetric estimation by permanganate is usually effected by sulphur dioxide, the pentoxide being reduced definitely by this reagent to the state of tetroxide. It has long been 
known that with zinc and dilute acid the reduction of the pentoxide proceeds approximately, but not definitely, to the dioxide, and this method is, therefore, incapable of being made use of in its simple form. Gooch and Gilbert (Amer. Journ. Sci., xv., 389) have recently shown that it is possible to reconvert the lower oxides so formed to the state of tetroxide by silver sulphate, but as this method is somewhat troublesome, and as in the sulphur dioxide reduction there is always a possibility of not completely expelling the excess of the gas by boiling, I was hopeful that the charged palladium might have carried the reduction of the pentoxide down to a point corresponding sharply with the formation of one of the lower oxides. Unfortunately, however, this does not appear to be the case. The results obtained show, in fact, that reduction proceeds beyond the stage of tetroxide, but that it does not stop sharply at a point corresponding with the formation of any of the lower oxides, and, consequently, cannot be used for the purpose of volumetrically estimating vanadium. Pure recrystallized ammonium metavanadate was used in my experiments, and it was found that, when the charged palladium is introduced into hot acidified solutions of this salt, the yellow colour rapidly changes to green, and soon after becomes blue, showing that reduction to $\mathrm{V}_{2} \mathrm{O}_{4}$ is readily effected. Unfortunately, as $\mathrm{I}$ bave indicated above, the reaction continues slowly after this point has been reached, and renders the process useless for quantitative purposes.

\section{Molybdenum.}

In these experiments specially-prepared molybdenum trioxide was employed, the purity of which was determined by (1) reduction in hydrogen at a red heat, (2) conversion into lead molybdate, and (3) reduction with zinc and hydrochloric acid. Weighed quantities of this compound were dissolved in a little caustic soda or ammonia, diluted with water, acidified, and treated with the charged palladium in the usual way. On boiling, the solution acquired a greenish colour, soon becoming greenish-brown. On titration with permanganate, it was found that only one-third of the molybdenum trioxide had apparently undergone reduction, but the palladium was coated with a brownish-black deposit (? hydrated $\mathrm{MoO}_{2}$ ). Other experiments made in this way having given similar results, the trioxide was dissolved in hot concentrated sulphuric acid, and the solution after dilution treated with the charged metal as before. In this case no deposit formed on the surface of the metal, and the solution rapidly acquired a deep reddish-brown colour. On titrating this at the end of three hours with potassium permanganate, it was found that reduction had proceeded slightly beyond the stage of dioxide, the result corresponding with 0.104 gramme $\mathrm{MoO}_{2}$, as against 0.100 gramme taken. In many other experiments conducted in a similar manner, it was found that, as in the case of vanadium, the reduction could not be carried to a definite stage, and only by chance could so good a result as that given above be obtained. In many cases the reduction proceeded to a point between the sesquioxide and dioxide, whilst in others it did not quite reach the latter stage.

\section{Cerium.}

For the purpose of these experiments, pure chloride of cerium was obtained from Kahlbaum and carefully examined. Hydrated ceric dioxide was prepared from this 
by the addition of an alkaline solution of sodium hypochlorite, and the yellow precipitate so obtained dried, after thorough washing, to a constant weight at $100^{\circ} \mathrm{C}$. 0.2 gramme of this compound yielded on ignition 0.1725 gramme $\mathrm{CeO}_{2}$, as against $0 \cdot 1728$ gramme required for the compound $2 \mathrm{CeO}_{2} \cdot 3 \mathrm{H}_{2} \mathrm{O}$. When weighed quantities of this hydroxide were dissolved in dilute acid, and the solution heated with the charged palladium, reduction to the cerous salt occurred; but attempts to titrate the resulting solution with permanganate failed, owing to the slowness with which the reaction appears to proceed and the uncertainty of the end-point. It was thought that this difficulty might possibly be overcome by adding to the reduced solution a known excess of potassium bichromate, and then titrating back with standard ferrousammonium sulphate. It was found, however, that a volume of the latter solution precisely equal to that of the bichromate taken was required, showing either that the ceric oxide had not undergone any reduction, or that this oxide was itself capable of oxidizing the ferrous solution. The latter explanation was found to be the correct one, and indicated a means not only of proving the complete reduction of ceric to cerous oxide by the charged palladium, but also of volumetrically estimating cerium. This method is still under investigation, and the results will be communicated to the Society shortly, but the following numbers may be given here. A weighed quantity of the hydrated dioxide was dissolved in dilute sulphuric acid, and titrated directly with an $\frac{\mathbb{v}}{10}$ solution of ferrous-ammonium sulphate:

$$
\begin{array}{ccccc} 
& & & \text { Found. } & \text { Taken. } \\
2 \mathrm{CeO}_{2} \cdot 3 \mathrm{H}_{2} \mathrm{O} & \ldots & \ldots & 0.0984 \text { gramme } & 0.100 \text { gramme } \\
& \ldots & \ldots & 0.1006, " & 0 \cdot 100 \text { ", }
\end{array}
$$

The essential reaction involved may be expressed by the equation :

$$
2 \mathrm{CeO}_{2}+2 \mathrm{FeSO}_{4}+\mathrm{H}_{2} \mathrm{SO}_{4}=\mathrm{Ce}_{2} \mathrm{O}_{3}+\mathrm{Fe}_{2}\left(\mathrm{SO}_{4}\right)_{3}+\mathrm{H}_{2} \mathrm{O} \text {. }
$$

It follows from the preceding that a solution of ferrous iron may be used for the purpose of ascertaining whether the charged palladium has completely reduced the ceric salt to the cerous state, and it was found that after treatment with the metal the ferrous solution was entirely unacted upon, and that even $1 \mathrm{drop}$ of an $\frac{\mathrm{E}}{1 \overline{0}}$ iron solution constituted an excess which could easily be recognised by testing with ferricyanide.

The investigation with which this paper is concerned was undertaken for the purpose of ascertaining to what extent palladium-hydrogen could be conveniently and with advantage employed in analytical processes involving reduction changes. I have not, therefore, thought it desirable to proceed further with those substances - e.g., bromates, iodates, etc.--which are attacked with considerable difficulty, for even if complete reduction could be secured by employing a very large amount of the charged metal and heating for a very long time, the process would be too troublesome to be of much practical use, and would present no advantage over existing methods. In those cases, however, in which reduction is readily brought about, the method is an admirable one, both in respect of simplicity and accuracy. The cost of the palladium is only a question of initial outlay, and, save in cases where a considerable number of reduction experiments would have to be carried out simultaneously, need not be considered. 
The "charging" of the metal is most readily effected by means of the main current passed through a suitable resistance, if direct, or through a transformer, if alternating. In laboratories which do not possess an electrical installation, an accumulator constitutes a convenient and economical source of current. It may be well to point out that only a small proportion of the total hydrogen is " evolved" in any of these experiments, and that, consequently, very little current suffices to recharge. Attempts were made to carry out some of the reductions under increased pressure, but the results were, as might perhaps have been foreseen, less satisfactory than those obtained in the ordinary way.

I feel that I cannot conclude this paper without alluding very briefly to the bearing which the results appear to have upon the nature of " palladium-hydrogen," although such a discussion is perhaps somewhat out of place in a communication dealing with analytical processes. It will be observed that I have throughout avoided the use of the words " occluded " and " combined," inasmuch as considerable differences of opinion still exist as to the nature of the substance to which we give the name "palladium-hydrogen." It is well known that Graham regarded it as an alloy containing "the volatile metal hydrogenium," and that subsequent observers, including Dewar, and Troost, and Hautefeuille, considering it to be a compound, have assigned to it such formulæ as $\mathrm{Pd}_{3} \mathrm{H}_{2}$ and $\mathrm{Pd}_{2} \mathrm{H}$. More recently the subject has been very carefully examined by Mond, Ramsay, and Shields, who appear to regard the evidence they have obtained as, on the whole, opposed to the theory of chemical combination. It is noteworthy that the question has throughout. been attacked almost entirely from what may be termed the physical side, conclusions for or against the existence of a chemical compound having been based upon the results obtained in the investigation of such properties as vapour pressure of palladium-hydrogen at different temperatures, the "heat of occlusion," and he influence of increased pressure on the quantity of hydrogen absorbed. The formula $\mathrm{Pd}_{3} \mathrm{H}_{2}$, on the other hand, was assigned to palladium-hydrogen because it represents fairly closely the actual composition of the fully-charged metal. The hydrogen in palladium-hydrogen may be simply occluded or condensed in the pores of the metal, or it may occur in the form of a solid solution, or it may exist in actual chemical combination, or, finally, it may be present in two or more of the above states.

This is not the place to enter into a close examination of these views, even if $I$ had obtained sufficient new experimental evidence to justify me in doing so ; but I may, perhaps, be permitted to say that the observations which I have made during the progress of my investigation appear to me to favour the view that the hydrogen exists at least partly in a state of chemical combination, and probably in two forms. It must, of course, be remembered that at the temperature of my experiments (approximately $100^{\circ} \mathrm{C}$.) only a part of the hydrogen is " evolved," but of this comparatively little (often not more than 5 per cent.) is concerned in the chemical reducing changes involved. In accordance with our present views it is the atomic, or " nascent," hydrogen alone that is capable of bringing about such changes, and a portion at least of the hydrogen must, therefore, be in this condition at the moment of separation. It is true that our knowledge of the precise nature of " occlusion" is comparatively slight; but it is, I think, much more probable that hydrogen which 
is evolved in the chemically active or atomic condition has resulted from the splitting up of a compound than that it has been formed in the process of being driven out of the pores of the metal in which it was condensed or liquefied, or while being liberated from a state of solution. I have obtained other evidence which points, I think, in the same direction, and I may possibly deal with this on another occasion.

It gives me much pleasure, in concluding, to gratefully acknowledge the capable assistance rendered to me in this work by my assistants, Mir. H. A. Thiersch and Mr. P. Whitteridge, B.Sc.

\section{Discussion.}

The President (Mr. Fairley) said that this peculiar alloy, or whatever it might be, of palladium and hydrogen had since its discovery been one of the most interesting of substances, whether from an analytical or from a purely scientific point of view. He had calculated what the apparent volume of the hydrogen in it might be, and had found that palladium absorbed, roughly speaking, about 1,000 times its volume of hydrogen, and in so doing expanded about one-tenth of its volume. Calculated from exact data, Dewar* found that the density of the hydrogen worked out to a mean value of 0.62 as compared with water. The pressure required to produce this result would be something like 10,000 atmospheres, so that obviously there was here something very wonderful, assuming-which was a very large assumption, bearing in mind the electric theory of matter - that palladium really filled up its own space. The action of ordinary hydrogen on silver solutions has been studied by Bunsen, Russell, and others (Journ. Chem. Soc., 1874, p. 3). Under ordinary circumstances a certain proportion of the silver present in a nitrate solution is precipitated by hydrogen previously purified by careful washing with excess of silver nitrate. But the whole of the silver cannot be so precipitated, as the reaction is a reversible one. It was interesting, comparing this reagent with others, to note some differences in its action. The reduction of ferric salts by means of sulphites, for instance, took place with great facility in the hands of some persons, while others experienced much difficulty. The point simply was that if the excess of acid in the ferric solution was kept very minute reduction was readily obtained, whereas if there were a large excess of acid one had to go on adding sulphite for some time before the reduction was complete. Apparently, with palladium-hydrogen an excess of acid did not interfere with the reduction. It would be interesting to extend the investigation to many of the organic colouring matters and such bodies as were readily reduced to leuco-compounds. In all probability palladium-hydrogen would prove as useful for such substances as for metallic oxides. He was not quite clear whether in the earlier experiments the palladium was charged by first heating it to redness and then cooling it slowly in a current of hydrogen, though no doubt, apart from the question of convenience, the same results would be obtained as by the method adopted by Mr. Chapman.

Mr. Herbert E. Burgess inquired whether Mr. Chapman had tried the action of palladium-hydrogen on any organic substance-for instance, for the reduction of

\footnotetext{
* Proc. Chem. Soc. 1897, p. 192.
} 
an aldehyde to an alcohol. A large field for research seemed to be open in this direction.

Mr. Henner said that possibly the comparative failure which Mr. Chapman had met with in certain cases-that, for instance, of chlorates-might be turned into success if a trace of a ferrous salt were present. Some years ago, in an investigation on the subject of chlorine determination, he (Mr. Hehner) had found that chlorates were readily reduced in acid solution by ferrous compounds. If a trace of iron were present with the palladium-hydrogen, the reducing action would be continuous, for the iron would go on reducing, the resulting ferric salt being itself reduced by the palladium-hydrogen.

Mr. A. J. Murphy inquired whether, before abandoning the attempt to reduce nitrates, Mr. Chapman had made experiments with such quantities as would be present in ordinary water. It would be interesting to know whether there was any chance of palladium-hydrogen proving a successful rival to the copper-zinc couple, because occasionally waters were met with which were rather stubborn, and required for complete reduction a much longer time than the one, two, or more hours usually regarded as sufficient.

Mr. Chapman, referring to the early experiment of Bunsen, of which the President had spoken, said that he also had some recollection of a statement that silver salts were reduced by hydrogen, but he should like to know (possibly someone present did) whether the experiment was made under such conditions as to preclude the possibility of any impurity in the hydrogen. He thought that for all practical purposes it might be taken that it was only the so-called "nascent" hydrogen that possessed this particular kind of activity; but he spoke subject to correction, as he did not remember the particulars of the experiment in question. He heartily agreed with the suggestions that had been made as to the application of this reducing agent to some of the reducible organic colouring matters. He had tried its action on acetic acid, and had found that after several hours' boiling with fully-charged palladium a trace of alcohol was formed. He believed it had been stated that nitrobenzene could be reduced to aniline in this way, but he had not confirmed that, and, in fact, had made no experiments with organic substances except the single one with acetic acid. He was very much indebted to Mr. Hehner for his suggestion. No doubt a lirace of ferrous salt would cause the reduction to be complete in some of the other cases. He had, however, concerned himself more particularly with the action of palladiumhydrogen from the scientific point of view; and it was only in the case of those substances which were reduced easily and readily that he had considered it worth while to work out the process fully. If it proved troublesome, complicated, likely to take a long time, and especially if it necessitated the introduction of some other substance as an intermediary, he did not consider that it would possess any advantage over existing methods. In all the four cases in which he had recommended it it was an excellent process. Iron was readily reduced, there were no products from the reducing agent, the end reaction was sharp, and the whole process was simple and cleanly. In the case of chromium (in which it was, perhaps, not quite so necessary) it worked equally well. With ferricyanides-for which at present there was no simple reducing process-it worked excellently, and it also gave good results with 
cerium. Probably in some of the other instances conditions could be found in which complete reduction would take place, but it was, perhaps, scarcely worth while pursuing the matter further in such cases, because satisfactory processes were already available. That answered Mr. Murphy's question with regard to nitrates. The nitrate solution used for these experiments had been a strong one, and he had not made any experiments with natural waters. He had always found the copper-zinc couple very satisfactory for quantities up to, say, 1 grain or 2 grains of nitric acid per gallon. For larger quantities he invariably used the Crum process. It was, however, quite possible that with such small quantities of nitrates as occurred in natural waters the reduction with palladium-hydrogen might be complete. 